\title{
Physiological and structural traits of the congeneric species Styrax ferrugineus and $S$. pohlii occurring in contrasting environments
}

\author{
Carolina M.S. Silva ${ }^{a}$, Ricardo Harakava ${ }^{\mathrm{b}}$, Julia Sonsin-Oliveira ${ }^{\mathrm{c}}$, Carmen R. Marcati ${ }^{\mathrm{d}}$, \\ Silvia R. Machado ${ }^{\mathrm{e}}$, Rafael V. Ribeiro ${ }^{\mathrm{f}}$, Gustavo Habermann ${ }^{\mathrm{g}, *}$ \\ ${ }^{a}$ Programa de Pós-Graduação em Ciências Biológicas (Biologia Vegetal), Universidade Estadual Paulista, UNESP, Instituto de Biociências, Departamento de Botânica, Av. \\ 24-A, 1515, 13506-900, Rio Claro, SP, Brazil \\ b Centro de P\&D de Sanidade Vegetal, Laboratório de Bioquímica Fitopatológica, Instituto Biológico, Av. Conselheiro R. Alves, 1252, 04014-002, São Paulo, SP, Brazil \\ ${ }^{\mathrm{c}}$ Instituto de Ciências Biológicas, Universidade de Brasília, UnB, Campus Universitário Darcy Ribeiro, Asa Norte, 70910-900, Brasília, DF, Brazil \\ ' Departamento de Ciência Florestal, Universidade Estadual Paulista, UNESP, Faculdade de Ciências Agronômicas, C.P. 237, 18603-970, Botucatu, SP, Brazil \\ e Departamento de Botânica, Universidade Estadual Paulista, UNESP, Instituto de Biociências, C.P. 510, 18618-970, Botucatu, SP, Brazil \\ ${ }^{\mathrm{f}}$ Department of Plant Biology, Institute of Biology, P.O. Box: 6109, University of Campinas - UNICAMP, 13083-970, Campinas, SP, Brazil \\ ${ }^{g}$ Departamento de Botânica, Universidade Estadual Paulista, UNESP, Instituto de Biociências, Av. 24-A, 1515, 13506-900, Rio Claro, SP, Brazil
}

\section{A R T I C L E I N F O}

Edited by Hermann Heilmeier

Keywords:

ABA

Cerrado

Gas exchange

NCED

Species distribution

Wood anatomy

\begin{abstract}
A B S T R A C T
Abscisic acid (ABA) attenuates stomatal conductance $(g s)$ and transpiration $(E)$ in response to drought. Broadly known as 'Brazilian savanna', the Cerrado sensu lato is a mosaic of landscapes, including savanna-type vegetation, such as the cerrado sensu stricto (s. str.), and riparian forests occurring along rivers. These habitats share floristic elements, and congeneric species are adapted to grow in these drought- and flood-prone environments. We assessed leaf concentration of ABA and its metabolites, as well as $g s, E$ and leaf water potential $(\Psi \mathrm{w})$ in shrubs of Styrax ferrugineus in a cerrado $s$. str. (savanna species) and in trees of $S$. pohlii in a riparian forest (forest species), in both the wet and dry seasons. We also quantified 9-cis epoxycarotenoid dioxygenase (NCED) gene expression in leaves, and wood anatomical features in stems. We expected that the forest species would not increase their leaf $\mathrm{ABA}$ content during the dry season because of the moist soil from the riparian forest. Regardless of the environment, both species expressed NCED, synthesized ABA, and exhibited reductions in both $\Psi_{\mathrm{W}}$ and $g s$ in the dry season, confirming these as universal responses to the dry season. The savanna species had more xylem vessels per $\mathrm{mm}^{2}$ and these vessels were narrower than those observed in stems of the forest species, resulting in a low vulnerability to cavitation $\left(l_{\mathrm{vul}}\right)$ estimated for both species. Our results demonstrate that, despite inhabiting contrasting habitats, these species display similar ecophysiological responses to the dry season and their wood anatomical features may explain their geographical distribution.
\end{abstract}

\section{Introduction}

Broadly defined as 'Brazilian savanna', the Cerrado vegetation is a mosaic of vegetation types, which includes the cerrado 'sensu stricto' ( $s$. $s t r$.), a savanna-type physiognomy. To cope with seasonal drought occurring between April and September, plants from this physiognomy reduce stomatal conductance $(g s)$, transpiration rates $(E)$ and leaf water potential $\left(\Psi_{\mathrm{w}}\right)$ (Da Veiga and Habermann, 2013; Prado et al., 2004). Tolerance to the dry season in these plants involves leaf deciduousness, low specific leaf area (leaf area per leaf mass - SLA) and deep roots (Franco, 1998; Franco et al., 2005; Habermann and Bressan, 2011). On the other hand, forest-type physiognomies, such as riparian forests, also occur along rivers and streams within the Cerrado, providing a water- influenced habitat for a large number of typical moist forest species (Oliveira Filho and Ratter, 2002). Trees from riparian forests invest in large SLA to improve light capture and reach the forest canopy (Habermann and Bressan, 2011).

Variation in $g s$ and related traits, such as transpiration and photosynthesis, is likely to be associated with abscisic acid (ABA) in species growing in savanna-type physiognomy. In fact, $A B A$ is involved in drought tolerance (Pinheiro and Chaves, 2011), acting mainly in the attenuation of $g s$ and $E$ (Chaves et al., 2002). Plants also respond to drought by expressing genes responsible for ABA biosynthesis and inactivation, modulating its endogenous concentration (Xiong and Zhu, 2003). Except for lycophytes and ferns, stomatal adjustments as a result of drought-induced ABA biosynthesis seem to be a universal response

\footnotetext{
* Corresponding author.

E-mail address: ghaber@rc.unesp.br (G. Habermann).
} 
among plants (Brodribb and McAdam, 2011; Pinheiro and Chaves, 2011; Xiong and Zhu, 2003), including Arabidopsis (Umezawa et al., 2006), tomato mutants (Thompson et al., 2004), and crop species (Heilmeier et al., 2007).

Compared with crop species, the association between ABA and leaf gas exchange of native species is relatively less reported (Heilmeier et al., 2007). During the dry season, higher leaf ABA concentration is expected in savanna species when compared with species from the riparian forest, which have shorter roots (Habermann and Bressan, 2011), minor ability to cope with seasonal drought (Hao et al., 2008), and grow on soaked soils (Kissmann et al., 2012). Wood anatomical features may also reflect the ability of species to inhabit contrasting environments. For instance, species from xeric habitats display high xylem vessel density in stems to avoid cavitation and endure increased vapor pressure deficits (VPD), while species from mesic habitats have low density of vessels with large lumens (Ewers et al., 2007).

When studying ABA, it is important to check the gene family expressing the 9-cis epoxycarotenoid dioxygenase (NCED) enzyme, a ratelimiting step in ABA biosynthesis (Tan et al., 2003) that may be induced by drought (Iuchi et al., 2001). In addition, ABA may be catabolized in many different compounds, such as phaseic acid (PA) and ABA- $\beta$-Dglucosyl ester (ABA-GE) (Zaharia et al., 2005).

To understand seasonal adjustments in savanna and forest species, we assessed leaf concentrations of ABA and its metabolites, as well as $\Psi_{\mathrm{W}}$ and leaf gas exchange in the dry and wet seasons. We also quantified NCED gene expression in leaves in the dry season and evaluated wood anatomical traits in stems. Adult shrubs of Styrax ferrugineus (Nees \& Mart.) naturally occurring in a cerrado s. str. and trees of $S$. pohlii (A. DC.) from a riparian forest were studied. We hypothesized that the forest species does not present a large seasonal variation in $g s$ and leaf ABA concentration because extensive drought-protective responses may not be required in the riparian forest (Kissmann et al., 2012). On the other hand, the contrary is expected for the savanna species, which faces seasonal drought. In addition, we evaluated stem anatomical traits related to the resistance against cavitation, aiming to describe structural specialization of these species to cope with seasonal drought.

\section{Material and methods}

\subsection{Site description, plant material and experimental design}

We assessed five trees of Styrax pohlii A. DC. (Styracaceae), herein named 'forest species', in the first extract (trees with 3-5 $\mathrm{m}$ in height) of a riparian forest remnant ( $32 \mathrm{ha} ; 24^{\circ} 00^{\prime} \mathrm{S}, 47^{\circ} 32^{\prime} \mathrm{W}$; $660 \mathrm{~m}$ of altitude), and five shrubs (2-4 $\mathrm{m}$ in height) of $S$. ferrugineus Ness \& Mart., herein named 'savanna species', in a cerrado $s$. str. fragment (260 ha; $22^{\circ} 13^{\prime} \mathrm{S}, 47^{\circ} 53^{\prime} \mathrm{W} ; 730 \mathrm{~m}$ of altitude). These fragments are located in the respective municipalities of Ajapi and Itirapina, in the central region of the state of São Paulo, Brazil.

The riparian forest remnant has a shallow water table, with high water availability (not less than $1 \mathrm{~g} \mathrm{H}_{2} \mathrm{O}$ per $\mathrm{g}$ soil) throughout the year (see data from 2009 and 2010 in Kissmann et al., 2012). It has an organic soil (Habermann and Bressan, 2011), which supports a closedcanopy forest comprised of trees with up to $20 \mathrm{~m}$ in height, enabling approximately $50 \mu \mathrm{mol} \mathrm{m} \mathrm{m}^{-2} \mathrm{~s}^{-1}$ of photosynthetic photon flux density (PPFD) at the ground level from 9:00 $\mathrm{h}$ to 17:00 $\mathrm{h}$ in the wet and dry seasons (see Habermann et al., 2011; Kissmann et al., 2012). The cerrado $s$. str. fragment shows trees and shrubs scattered on a sandy soil (Habermann and Bressan, 2011) containing not more than $0.10 \mathrm{~g} \mathrm{H}_{2} \mathrm{O}$ per $g$ soil throughout the year (see data from 2009 and 2010 in Kissmann et al., 2012). The herbaceous understory receives $1200-1500 \mu \mathrm{mol} \mathrm{m}^{-2} \mathrm{~s}^{-1}$ of PPFD from 9:00 $\mathrm{h}$ to 13:00 $\mathrm{h}$ during the wet season and $800-1000 \mu \mathrm{mol} \mathrm{m}^{-2} \mathrm{~s}^{-1}$ during the dry season (see Habermann et al., 2011; Kissmann et al., 2012).

A climatic station located approximately $20 \mathrm{~km}$ from the riparian forest remnant and $40 \mathrm{~km}$ from the cerrado $s$. str. fragment registered $247.2 \mathrm{~mm}$ of rainfall within the period of 30 days prior to measurements at the end of the wet season (Feb/2011), when the air temperature was $23.8 \pm 1.1^{\circ} \mathrm{C}$. In the middle of the dry season (Aug/ 2011), the air temperature was $19.8 \pm 1.2^{\circ} \mathrm{C}$, and no rainfall was registered within the period of 30 days before evaluations.

For both species, the canopy of each of the five plants was subdivided into quadrants (north, south, east and west). Fully expanded sun-exposed leaves from the medium canopy position in these quadrants were used (in vivo) for measuring gas exchange, and also collected for measuring leaf water potential and quantifying ABA metabolites in the wet and dry seasons (although the riparian forest does not necessarily experience lack of water in the soil throughout the year, we refer to the 'dry season' for both experimental areas). We also measured the expression of NCED gene in the dry season. Stems of approximately $1 \mathrm{~cm}$ in diameter were collected from three plants for quantitative anatomical analysis, which enabled the structural characterization of each species. In addition, we performed scanning electron microscopy (SEM) qualitative analysis to describe micromorphological differences between the leaves of both species.

\subsection{ABA analysis}

After collecting 8 leaves (2 leaves from each of the four quadrants) per each of the five plants, the leaves were wrapped in aluminum foil, and frozen in liquid nitrogen for subsequent storage at $-80^{\circ} \mathrm{C}$ in an ultra-freezer. The main oxidative route of $\mathrm{ABA}$ is the $8^{\prime}$ hydroxylation, which produces 8'-hydroxyABA (Cutler and Krochko, 1999). This compound isomerizes to phaseic acid (PA), which may be reduced to dihydrophaseic acid (DPA) (Okamoto et al., 2009). Oxidation of 9methyl group of ABA also occurs, resulting in neophaseic acid (neoPA). A minor existing oxidative route produces (+)-7'-hydroxy-ABA (7'OHABA), whereas a minor reductive pathway produces an unstable $1^{\prime}, 4^{\prime}$-diol ABA. ABA and its metabolites may also be conjugated with glucose to form glycosylated esters corresponding to $\mathrm{C} 1, \mathrm{ABA}-\beta$-D-glucosyl ester (ABA-GE) or glycosides at C-1' or C-4' (Zaharia et al., 2005). To measure the concentrations of ABA, ABA-GE, PA, DPA, neoPA and 7'OHABA we used the method described by Silva et al. (2012). Leaf samples were ground, using a pestle, inside a porcelain mortar containing cold $\left(4{ }^{\circ} \mathrm{C}\right)$ solution of methanol:water:acetic acid (10:89:1 v:v:v) and $30 \mathrm{ng}$ of each labeled standard of $\mathrm{d}_{6}-\mathrm{ABA}, \mathrm{d}_{5}-\mathrm{ABA}-$ GE, $d_{3}$-DPA, $d_{3}-$ PA, $d_{4}-7^{\prime}-$ OHABA and $d_{3}$-neoPA, which were used as surrogates. This solution was loaded onto a solid phase extraction (SPE) and the cartridge was eluted using methanol:water:acetic acid (80:19:1 v:v:v). The eluted phase was dried and reconstituted using methanol:water (30:70 v:v) containing $0.1 \%$ formic acid. The extraction was performed in duplicate, and chromatographic analyses were done in triplicate for each extract.

ABA and its metabolites were analyzed using a liquid chromatograph (Agilent 1200 series) coupled to an electrospray ionizationtandem mass spectrometer (ESI-MS/MS) system (3200 QTrap; Applied Biosystems/MDS Sciex) using a reversed-phase column (Agilent, C18, $150 \mathrm{~mm} \times 4.6 \mathrm{~mm} \times 5 \mu \mathrm{m}$ ). The mobile phase consisted of methanol (A) and water (B), both containing $0.1 \%$ formic acid in the gradient elution mode. The A:B elution was performed using 50\% B and increased to $80 \% \mathrm{~B}$ over $7.5 \mathrm{~min}$ and then switched to $100 \% \mathrm{~B}$ over $2.5 \mathrm{~min}$, remaining at $100 \% \mathrm{~B}$ for $2.0 \mathrm{~min}$. The re-equilibration time was $5.0 \mathrm{~min}$. The flow rate was $500 \mu \mathrm{L} \mathrm{min}^{-1}$, and the injection volume was $20 \mu \mathrm{L}$.

\subsection{Gas exchange rates}

Leaf $\mathrm{CO}_{2}$ assimilation $(A)$ and transpiration rates $(E)$, and stomatal conductance $(g s)$ were measured with an open portable gas exchange system (LI-6400, LI-COR, Lincoln, NE, USA). Water use efficiency (WUE $=A / E$ ) and intrinsic water use efficiency (IWUE $=A / g s$ ) were 
also calculated. Leaves were assessed between 9:00 h and 10:30 $\mathrm{h}$ for daily maximum $A$ (Feistler and Habermann, 2012), and when gs values best reflect the leaf water status, potentially enabling gas exchange (Medrano et al., 2002). We used 1-2 leaves from sun-exposed quadrants of each of the five plants.

The air temperature and vapor pressure deficit (VPD) within the (sample) leaf chamber (standard $2 \mathrm{~cm} \times 3 \mathrm{~cm}$, LI-COR) were allowed to vary with the external environment. Nevertheless, the cerrado $s$. str. is an open savanna-type physiognomy, in which the discontinuous canopy allows heavy irradiation load on the ground, whereas in the riparian forest the evaporative demand is naturally lower than the cerrado s. str. (see Habermann et al., 2011; Kissmann et al., 2012). Therefore, VPD within the (sample) leaf chamber was $1.83 \pm 0.12 \mathrm{kPa}$ in the wet season and $2.00 \pm 0.30 \mathrm{kPa}$ in the dry season when measuring the savanna species in the cerrado s. str; and $1.06 \pm 0.11 \mathrm{kPa}$ in the wet season and $1.32 \pm 0.27 \mathrm{kPa}$ in the dry season when measuring the forest species in the riparian forest remnant. The PPFD within the leaf chamber was provided by an artificial red (90\%) and blue (10\%) LED light source (6400-02B, LI-COR), and it was set to $1500 \mu \mathrm{mol} \mathrm{m}{ }^{-2} \mathrm{~s}^{-1}$ when measuring both species in their respective environments. This PPFD value returns saturating $A$ for both the savanna and forest species (Da Veiga and Habermann, 2013).

\subsection{Leaf water potential}

The leaf water potential at predawn $\left(\Psi_{\mathrm{pd}}\right)$ and midday $\left(\Psi_{\mathrm{md}}\right)$ was measured by the pressure chamber method (Turner, 1981), using a DIK7000 (Daiki Rika Kogyo, Tokyo, Japan) chamber. Midday leaf water potential was assessed between 14:00 h and 15:00 h, when the highest VPD is found. In each of the five plants, we used one leaf per plant, randomly choosing a quadrant for $\Psi_{\mathrm{pd}}$; for $\Psi_{\mathrm{md}}$, we used one leaf from the most sun-exposed quadrant.

\subsection{Gene expression analysis}

After collecting 8 leaves (2 leaves from each of the four quadrants) per each of the five plants, assays were performed using samples collected in the dry season, following the suggestions given by the MIQE guidelines (Bustin et al., 2009). Degenerate primers were designed according to conserved regions of mRNA sequences of the 9-cis epoxycarotenoid dioxygenase (NCED) enzyme, and of actin and elongation factor genes in other plant species registered in the GenBank (actin: forward 5'-ATGTAYGTTGCYATHCAGGC-3', reverse 5'-AYCTGYTGRAAKGTGCTKAGG-3'; elongation factor: forward 5'-ATCTACAAGYTKGGWGGWAT-3', reverse 5'-GGDAMCKRAGDGGYTTGTC-3'; and NCED: forward 5'-GGCGAGCTHCACGGCMA-3', and reverse 5'-GCGTTCCAGAGGTRGA-3'). Total DNA was extracted from leaf samples using the DNeasy plant mini kit (Qiagen, Hilden, Germany), and amplified using the designed degenerate primers. The PCR products were sequenced and new internal primers were designed for qRT-PCR analysis of the Styrax genes. The internal primers for actin were: forward $5^{\prime}$-AGCTGGAGACTGCAAAGAGC-3' and reverse 5'-TTCCATTCCAATCAATGACG3', for elongation factor: forward 5'-GCAACCACGCCAAAGTATTC-3' and reverse $5^{\prime}$-TGTTGTCACCCTCAAAACCA- $3^{\prime}$, and for NCED: forward 5'-GAGCAACTCCACTCCACCA-3' and reverse 5'-GGTAAGGCTTTTGGATGACG-3'.

Serial dilutions of genomic DNA from both species were amplified using the internal primers in order to access the amplification efficiency during qPCR analysis. The LightCycler 480 SYBR Green I Master (Roche, Vilvoorde, Belgium) was used as the reagent in these tests, with the following procedural specifications: $95^{\circ} \mathrm{C}$ for $5 \mathrm{~min}(1$ cycle $), 95^{\circ} \mathrm{C}$ for $10 \mathrm{~s}, 58^{\circ} \mathrm{C}$ for $5 \mathrm{~s}, 72{ }^{\circ} \mathrm{C}$ for $30 \mathrm{~s}$ ( 40 cycles) followed by a melting curve analysis ( $1 \%$ slope temperature; $60-95^{\circ} \mathrm{C}$ ). Amplification efficiencies, respectively for actin, elongation factor and NCED were $112.1 \%, 116.4 \%$ and $109.6 \%$ for the savanna species and $99.7 \%, 98.6 \%$ and $99.7 \%$ for the forest species.
For quantitative analysis of NCED expression, total RNA was extracted from leaf samples using the RNeasy plant mini kit (Qiagen, Hilden, Germany). Total RNA (2 $\mu \mathrm{g})$ was treated with RNase-free TURBO DNase (Ambion, Carlsbad, USA) and transcribed in reverse to cDNA using an oligo-dT primer and Super Script III, according to the manufacturer's protocol (Life Technologies, Carlsbad, USA). The cDNAs were submitted to the NCED gene expression analysis using actin and the elongation factor genes in order to normalize the cycle threshold (Ct) values. The reagent and cycles used for the qRT-PCR analysis were the same as those used for the amplification efficiency tests. In this protocol, every reaction was performed in triplicate.

\subsection{Anatomical features}

For light microscopy, samples (ca. $1 \mathrm{~cm}$ in diameter and $10 \mathrm{~mm}$ in length) from the middle region of mature stems were softened and sectioned with a rotary microtome. The sections $(3-5 \mu \mathrm{m})$ were double stained with aqueous $1 \%$ safranin and aqueous $1 \%$ astra blue (Bukatsch, 1972) (1:9; v:v) and fixed with butyl acetate. Histological slides were mounted permanently in synthetic resin (Entellan ${ }^{\circ}$ ). The cells were dissociated using Franklin's method (1945), modified by Kraus and Arduin (1997), and stained with aqueous 1\% safranin (Sass, 1940). Semi-permanent slides were mounted in glycerin diluted in water (1:1; v:v).

For SEM qualitative analysis, leaf samples (1-2 leaves) were fixed in glutaraldehyde $(2.5 \%$ with $0.1 \mathrm{M}$ phosphate buffer, at $\mathrm{pH} 7.3$; overnight at $4{ }^{\circ} \mathrm{C}$ ), dehydrated in a graded acetone series, dried to the critical point, mounted on aluminum stubs, gold-coated and examined with a Phillips 515 scanning electron microscope.

For quantitative data, 10 measurements (counts) per each of the three plants were made for vessel element length $(\mu \mathrm{m})$ and vessel density (number of vessels per $\mathrm{mm}^{2}$ ), vessel lumen diameter $(\mu \mathrm{m})$, intervessel and vessel-ray pit diameter $(\mu \mathrm{m})$, and perforation plate diameter $(\mu \mathrm{m})$. The perforation plate diameter was measured in radial sections, at the widest part of the opening, excluding the wall.

To associate the above-mentioned quantitative anatomical parameters with hydraulic-related vessel peculiarities, we also calculated the theoretical specific conductivity $\left(k_{\mathrm{t}} ; \mathrm{kg} \mathrm{m}^{-1} \mathrm{~s}^{-1} \mathrm{MPa}^{-1}\right)$, as $k_{\mathrm{t}}=\pi \mathrm{r}_{\mathrm{w}} / 64 \eta \mathrm{A}_{\mathrm{x}}$, where $\rho_{\mathrm{w}}$ is the density of water $\left(\mathrm{kg} \mathrm{m}^{-3}\right), \mathrm{A}_{\mathrm{x}}$ is the sampled cross-sectional area of xylem $\left(\mathrm{m}^{2}\right)$ and $\eta$ is the dynamic viscosity of water (MPa s). This parameter represents the lumen conductance, omitting the resistance between xylem vessels, and it was calculated according to Lewis and Boose (1995). In addition, we calculated the cavitation vulnerability index $\left(l_{\mathrm{vul}}\right)$ as the ratio between the mean vessel diameter $(\mu \mathrm{m})$ and the vessel density, according to Arbellay et al. (2012). High values of $l_{\text {vul }}$ indicate high xylem functional vulnerability to water stress (cavitation).

\subsection{Data analysis}

Endogenous concentrations of $\mathrm{ABA}$ metabolites, gas exchange parameters and leaf water potential were subjected to student's $t$-test $(\alpha=0.05)$ to verify differences between the wet and dry season for each species. NCED quantitative gene expression and quantitative wood anatomical parameters were compared between species (student's $t$ test, $\propto=0.05$ ).

\section{Results}

Endogenous leaf ABA and PA concentrations were higher in the dry when compared to the wet season for both species (Fig. 1A,C). Leaf concentrations of 7'OHABA, neoPA and DPA showed the opposite response pattern, with values obtained in the dry season being lower than those obtained in the wet season (Fig. 1D-F). Although leaf ABA-GE concentrations significantly increased in both species in the dry when compared to the wet season, for the savanna species it showed a three- 


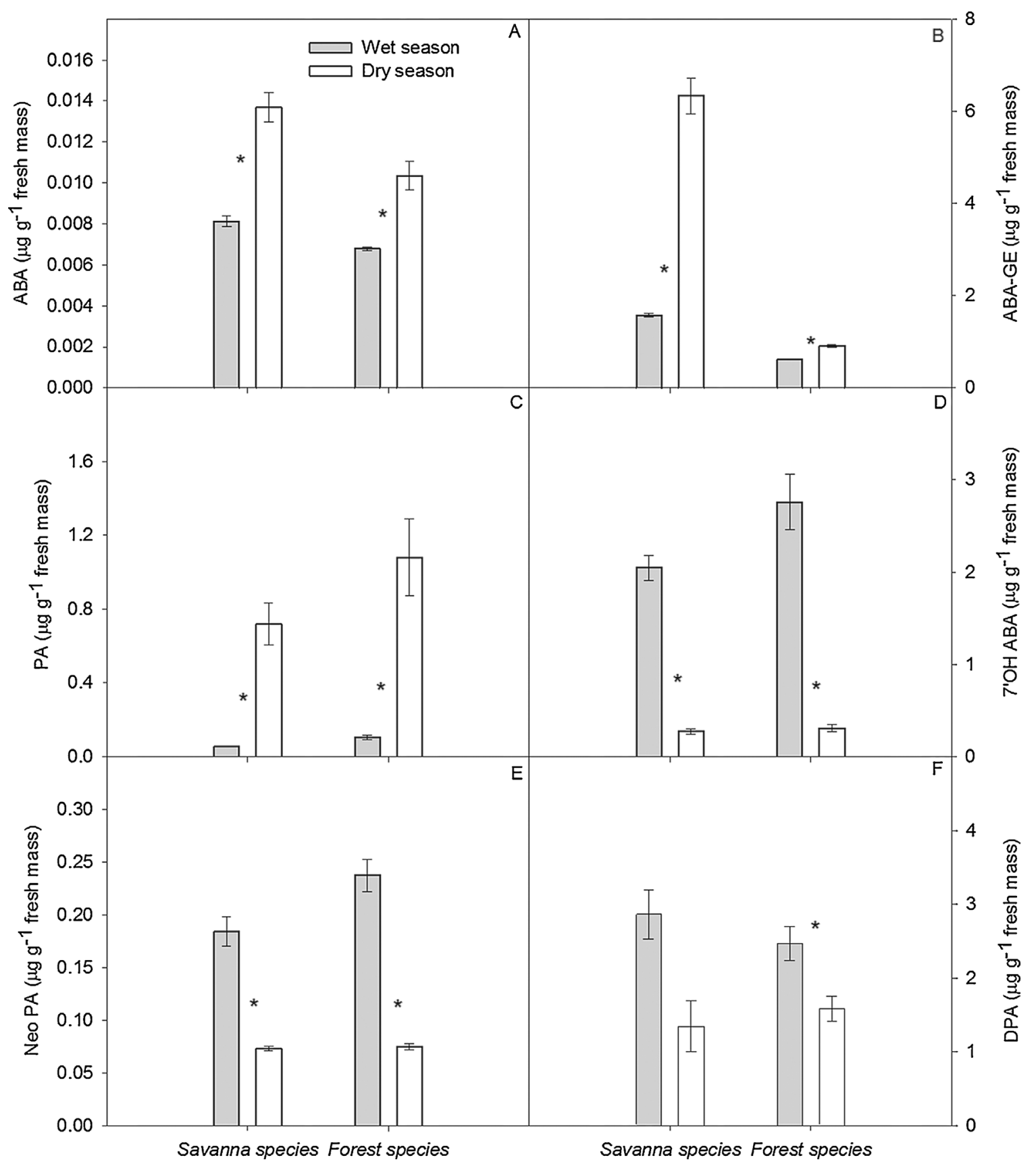

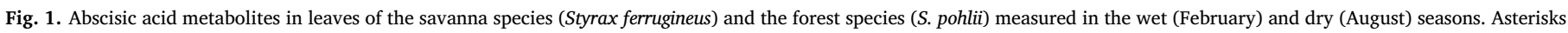

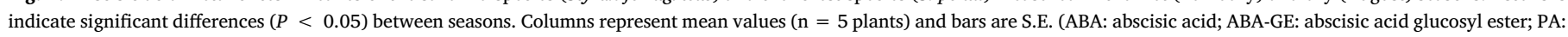
phaseic acid; 7'OHABA: (+)-7'-hydroxy-abscisic acid; Neo PA: neophaseic acid; DPA: dihydrophaseic acid).

fold increase while in the forest species it increased by $50 \%$ (from $0.60 \pm 0.005$ to $0.91 \pm 0.02 \mu \mathrm{g} \mathrm{g}^{-1}$; Fig. 1B). The NCED gene expression measured in the dry season revealed no difference between the savanna and forest species $(0.64 \pm 0.14$ vs. $0.53 \pm 0.10$ in the savanna and forest species respectively).

As leaf $\mathrm{CO}_{2}$ assimilation $(A)$, stomatal conductance $(g s)$ and transpiration $(E)$ of the savanna species were high in the wet season and all decreased at a similar proportion in the dry season (Fig. 2A-C), this species was able to maintain similar water use efficiency and intrinsic water use efficiency in both seasons (Fig. 2D,E). In the forest species, however, only $A$ and $g s$ decreased in the dry season in relation to the wet season (Fig. 2A,B), with plants transpiring similarly in both seasons (Fig. 2C). As a consequence, the forest species was able to maintain IWUE between seasons (Fig. 2E), but not WUE (Fig. 2D).
Both $\Psi_{\mathrm{pd}}$ and $\Psi_{\mathrm{md}}$ were significantly lower in the dry season in relation to the wet season (Fig. 3A,B). However, $\Psi_{\mathrm{pd}}$ of the savanna species was twice as low in the dry when compared to the wet season, whereas in the forest species this reduction was six-fold higher (Fig. 3A).

In relation to the forest species, stems of the savanna species showed four times more vessels per $\mathrm{mm}^{2}$, vessel elements were $40 \%$ shorter and their lumen diameter was $25 \%$ smaller (Fig. 4A,B; Table 1). Consequently, the theoretical specific conductivity $\left(k_{\mathrm{t}}\right)$ and $l_{\mathrm{vul}}$ were also lower in the savanna species when compared to the forest species (Table 1).

The abaxial leaf surface of the forest species had a thick trichome layer, preventing the observation of stomata (Fig. 4D,G). On leaves of the savanna species the trichome layer was less thick (Fig. 4C), enabling 


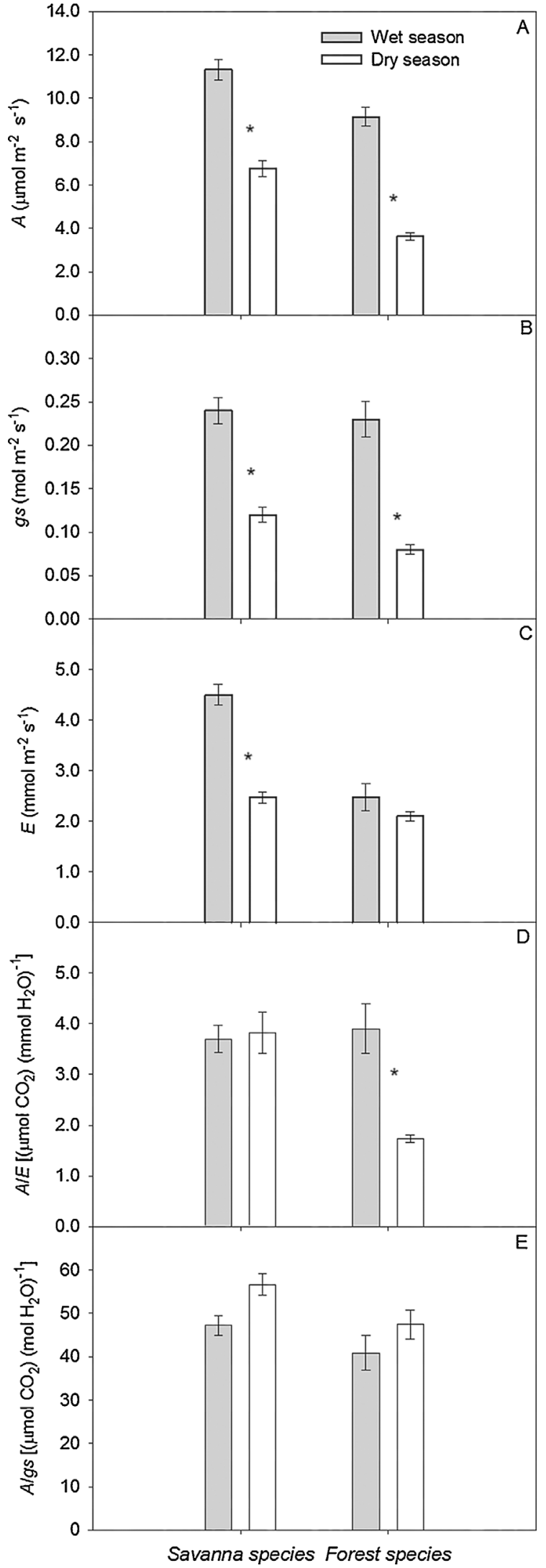

Fig. 2. Leaf gas exchange parameters of the savanna species (Styrax ferrugineus) and the forest species ( $S$. pohlii) measured in the wet (February) and dry (August) seasons. Asterisks indicate significant differences $(P<0.05)$ between seasons. Columns represent mean values ( $\mathrm{n}=5$ plants) and bars are S.E. $\left(A: \mathrm{CO}_{2}\right.$ assimilation rate; gs: stomatal conductance; $E$ : transpiration rate; $A / E$ : water use efficiency; $A / g s$ : intrinsic water use efficiency). the observation of clusters of stomata (Fig. 4E) within crypts (Fig. 4F).

\section{Discussion}

4.1. Seasonal changes in ABA-related metabolites, gas exchange and water status of congeneric species in contrasting environments

Our initial hypothesis about seasonal changes in leaf ABA concentration was corroborated only for the savanna species. Compared with the wet season, leaf ABA concentration measured in the dry season increased by $42 \%$ in the savanna species and $33 \%$ in the forest species (Fig. 1A). Although measured only in the dry season, NCED gene expression indicated ABA biosynthesis in the dry season not only in the savanna species, but also in the forest species, which inhabits a moist environment with high soil water availability even in dry seasons (Kissmann et al., 2012). It is likely that this increase in ABA concentration in leaves of both species caused reduction in $g s$ and $A$.

We could not demonstrate how much of the ABA found in leaves came from the roots, as the relationship between high root ABA concentration and low gs has also been reported (Yang and Guo, 2007). Collecting roots from field-grown native species is not only difficult, but may also result in unreliable data because samples could come from roots at different developmental stages. Furthermore, transcriptional regulation studies indicate that $\mathrm{ABA}$ is produced predominantly in plant shoots (Boursiac et al., 2013), although we cannot exclude the possibility that in the present study part of it could have come from roots or shoots. Accordingly, it has been demonstrated that gs reduction is primarily due to increased ABA biosynthesis occurring in leaves rather than in roots (Holbrook et al., 2002; Sauter et al., 2001; Thompson et al., 2007). In Arabidopsis, there are five NCED genes involved in ABA biosynthesis, but AtNCED3 is the most drought-induced gene occurring in leaves (Tan et al., 2003). In the present study, we obtained a single amplification product for both savanna and forest species using NCED degenerate primers. To be certain about the association between this 'amplification product' and AtNCED3, we performed a cluster analysis that showed highest phylogenetic proximity to AtNCED3 (data not shown). This suggests that most ABA measured in the dry season was synthesized in leaves of both species.

ABA-GE is an important long-distance signal (Davies et al., 2005; Sauter et al., 2002), which is stored in vacuoles when drought is imposed, and $\beta$-glucosidase enzyme can release free ABA (from ABA-GE) after drought (Han et al., 2012; Lee et al., 2006). ABA-GE and ABA concomitantly increase in leaves of barley plants subjected to drought (Thameur et al., 2011). As the ABA-GE concentration peak may also occur within 30 days before the ABA peak (López-Carbonell et al., 2009), part of the ABA found in the dry season would be a product of ABA-GE breakdown for both species.

Under drought conditions, the equilibrium between biosynthesis and catabolism tends to be shifted to ABA biosynthesis, but inactivation reactions also occur, and PA is the first inactive ABA metabolite to be formed from 8'hydroxylation (Okamoto et al., 2009). Our results reiterate this pathway as PA concentration increased in both species in the dry season and also revealed that both species express NCED and synthesize ABA (and ABA-GE) in leaves, reducing gs and contributing to conservation of water, especially in the savanna species.

Curiously, $\Psi_{\mathrm{pd}}$ of the forest species was almost three times lower $(-0.66 \pm 0.04 \mathrm{MPa})$ than that of the savanna species $(-0.23 \pm 0.01 \mathrm{MPa}$; Fig. $3 \mathrm{~A})$ in the dry season. This index reflects the nocturnal rehydration capacity of plants (Franco, 1998; Habermann et al., 2011; Turner, 1981) and could falsely suggest that the forest species faced a drought stress in a moist environment. However, $S$. pohlii presents $\Psi_{\mathrm{pd}}$ values close to $-0.5 \mathrm{MPa}$ even under well-watered conditions (Kissmann et al., 2014). 


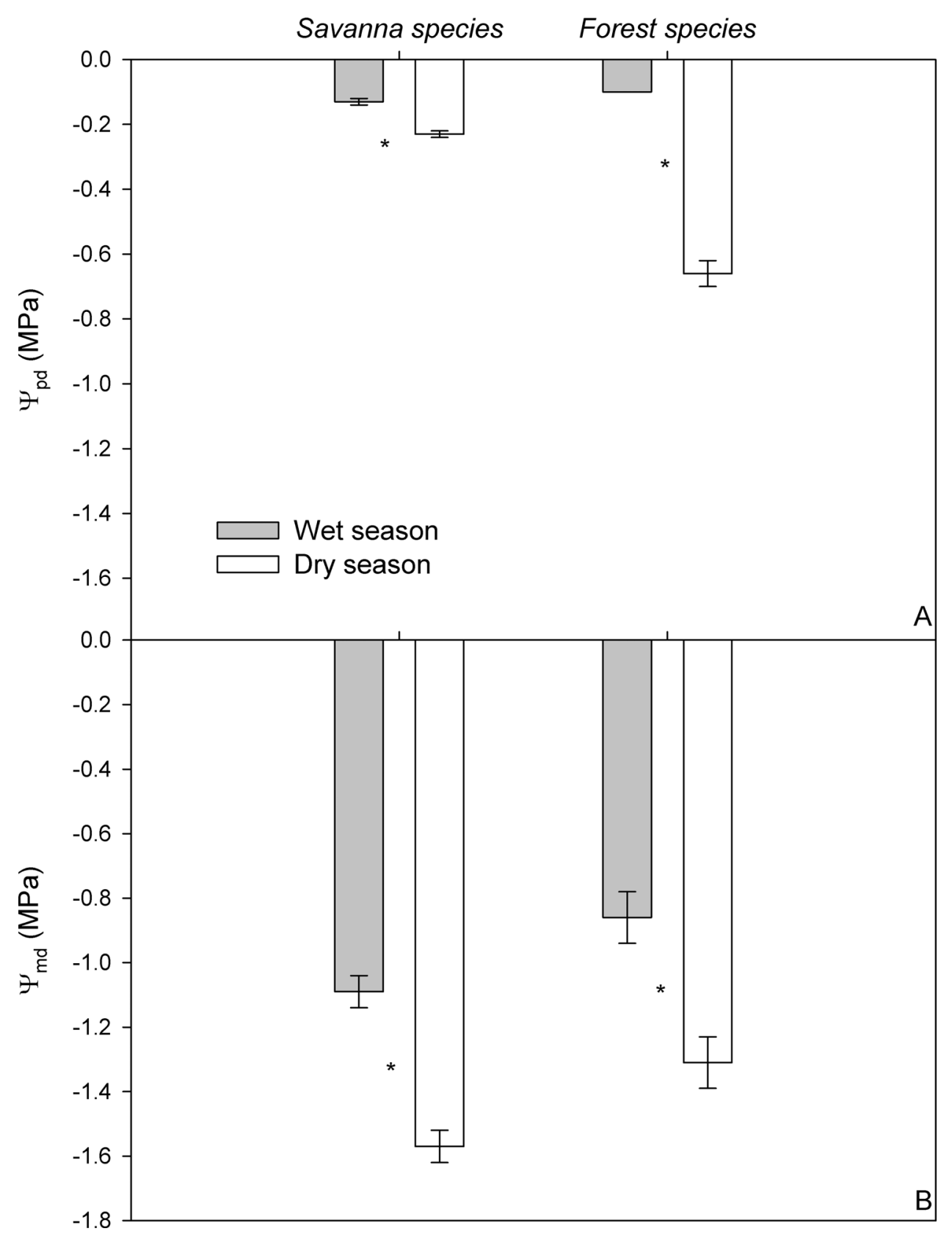

Fig. 3. Leaf water potentials of the savanna species (Styrax ferrugineus) and the forest species (S. pohlii) measured in the wet (February) and dry (August) seasons. Asterisks indicate significant differences $(P<0.05)$ between seasons. Columns represent mean values $(\mathrm{n}=5$ plants $)$ and bars are S.E. $\left(\Psi_{\mathrm{pd}}\right.$ : predawn leaf water potential; $\Psi_{\mathrm{md}}$ : midday leaf water potential).

\subsection{The connection between structural and functional traits and its importance for species distribution}

We also observed that the forest species showed similar transpiration rate in the wet and dry seasons, while the savanna species showed a decrease (-50\%) in leaf transpiration in the dry season (Fig. 2C). Although both species showed a decrease in $g s$ in the dry season, in the forest species this reduction was not associated with a concomitant decrease in leaf transpiration. This result would suggest that the transpiration of the forest species was already low in the wet season or that it maintains similar transpiration rates throughout the year. While gs is influenced by soil water availability (Chaves et al., 2002) and leaf ABA concentration (Holbrook et al., 2002; Sauter et al., 2001; Thompson et al., 2007), transpiration responds to VPD and hydraulic conductance of the soil-to-leaf pathway (Meinzer, 2003), which involves wood anatomical features. Regarding the atmospheric demand, both species were subjected to an increase of $10-20 \%$ in VPD in their respective habitats when comparing the wet season to the dry season. However, the VPD range was lower in the riparian forest (1.06-1.32 $\mathrm{kPa}$ ) than in the cerrado s. str. (1.83-2.00 kPa). Habermann et al. (2011) and Kissmann et al. (2012) have also found this VPD pattern in both environments, which reinforces the fact that the atmospheric demand is low in the riparian forest, a water-influenced habitat. Regarding wood anatomical features, the forest species had fewer xylem vessels per $\mathrm{mm}^{2}$, and these were long and wide (large lumen diameter), resulting in higher $k_{\mathrm{t}}$ and $l_{\mathrm{vul}}$ (Table 1 ). Similarly, low xylem vessel density was reported in a hybrid aspen (Populus tremula L. $\times$ P. tremuloides Michx.) grown under low atmospheric demand (Jasińska et al., 2015). Longer and wider xylem vessels found in forest species are more efficient in water conduction but have higher vulnerability to hydraulic dysfunctions (embolism) depending on the level of hydraulic tension a species experiences (Ewers et al., 2007). In addition, the forest species is leafy and shows elevated specific leaf area (Habermann and Bressan, 2011), which could increase the probability of cavitation and organ death (Ewers et al., 2007). In fact, more branches with more leaves are associated with an increased vulnerability to hydraulic dysfunction 


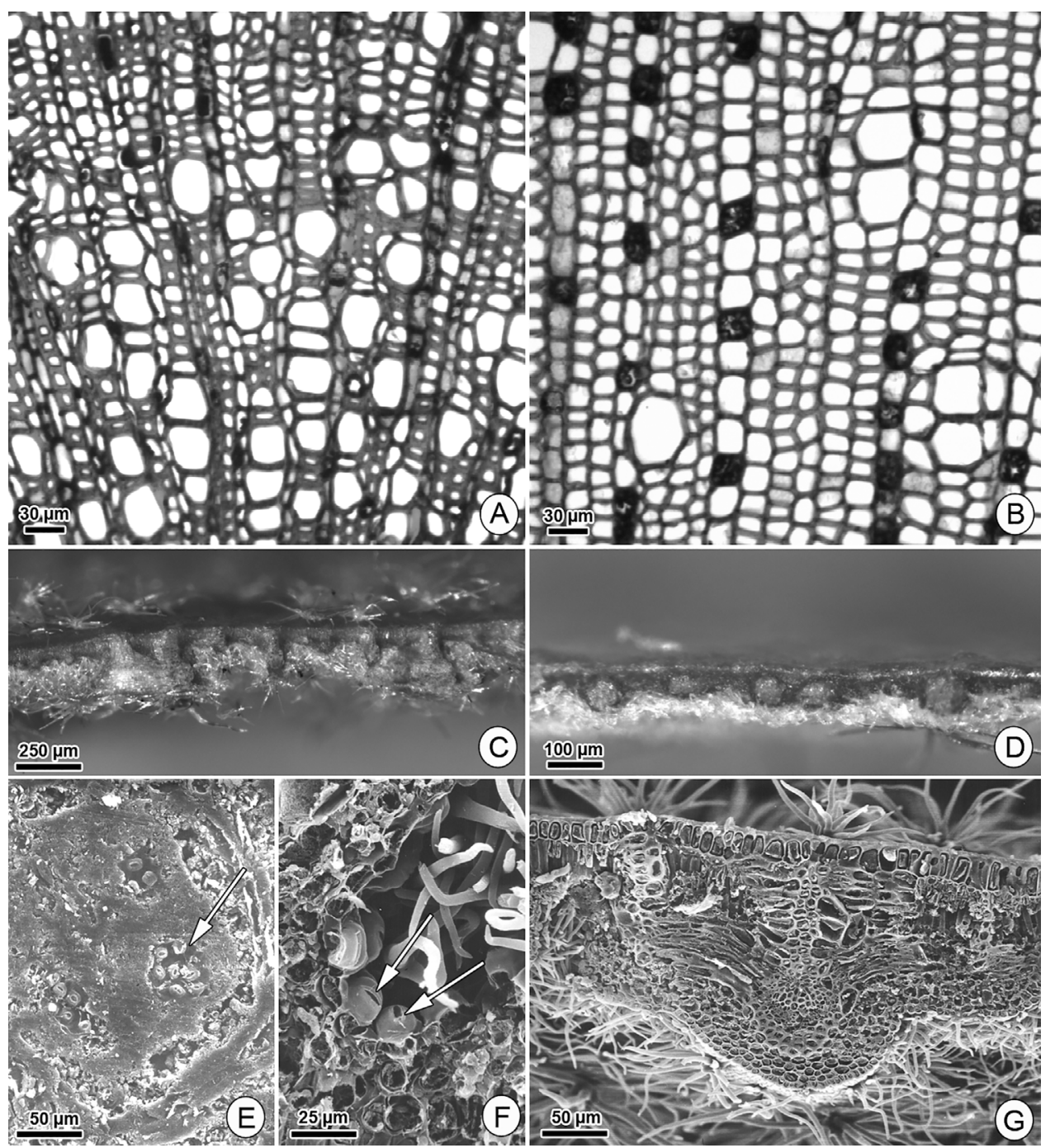

Fig. 4. Light microscopy of stems (A and B), view through a stereomicroscope (C and D), and SEM photographs of leaves (E, F and $\mathrm{G}$ ) of the savanna species (Styrax ferrugineus; A, C, E and F) and the forest species (S. pohlii; B, D and G). (A, C-F) savanna species: stem in cross section (A), general view of leaf in cross section (C), abaxial leaf surface with arrow indicating clusters of stomata (E) within crypts (F); (B, D and G) forest species: stem in cross section (B), general view of leaf in cross section (D) and leaf mesophyll in cross section (G).

Table 1

Quantitative wood anatomical features of vessel elements of trees of the savanna species (Styrax ferrugineus) and forest species (S. pohlii) occurring, respectively, in a Cerrado $s$. str. remnant (Itirapina, SP, Brazil) and in a riparian forest fragment (Ajapi, SP, Brazil).

\begin{tabular}{lll}
\hline & Savanna species & Forest species \\
\hline Vessel element length $(\mu \mathrm{m})$ & $507 \pm 42.11 b$ & $806 \pm 64.50 a$ \\
Pit diameter $(\mu \mathrm{m})$ & $3.0 \pm 0.12 a$ & $4.0 \pm 0.10 a$ \\
Perforation plate diameter $(\mu \mathrm{m})$ & $20 \pm 1.80 b$ & $33 \pm 2.29 a$ \\
$\quad$ Vessel lumen diameter $(\mu \mathrm{m})$ & $26 \pm 1.20 b$ & $35 \pm 2.08 a$ \\
Vessel density (vessels $\left./ \mathrm{mm}^{2}\right)$ & $164 \pm 5.88 a$ & $42 \pm 2.75 b$ \\
$\begin{array}{l}\text { Theoretical specific conductivity } \\
\quad\left(\mathrm{kg} \mathrm{m}^{-1} \mathrm{~s}^{-1} \mathrm{MPa}^{-1}\right)\end{array}$ & $5.00 \pm 0.14 b$ & $6.84 \pm 0.41 a$ \\
$\quad$ Susceptibility to cavitation $\left(l_{\mathrm{vul}}\right)$ & $0.16 \pm 0.0 b$ & $0.83 \pm 0.04 a$ \\
\hline
\end{tabular}

Mean values $(\mathrm{n}=3$ plants $\times 10$ measurements per plant $) \pm$ standard error; Different letters on rows represent significant difference $(P<0.05)$ between species.

(Hukin et al., 2005; Tyree and Ewers, 1991). Therefore, the anatomical and morphological traits observed here for the forest species would favor vessel cavitation under a highly demanding atmosphere, such as in the cerrado $s$. str. In contrast, short vessel elements and high vessel density, exhibiting lower lumen diameter and reduced $k_{\mathrm{t}}$ and $l_{\mathrm{vul}}$ were observed in the savanna species (Table 1). These characteristics are associated with low cavitation vulnerability but, most importantly, they promote xylem safety under drought-prone environments (Ewers et al., 2007). Taken together, these results suggest that the savanna species may be more adapted to drought-prone habitats, such as the cerrado $s$. $s t r$, while the forest species fits in an environment where water is hardly scarce in the soil and the atmospheric demand is relatively low, such as in the riparian forest.

In conclusion, we show that $\mathrm{ABA}, \mathrm{ABA}-\mathrm{GE}$ and $\mathrm{PA}$ increased in both species in response to the dry season, and NCED gene is also expressed in the leaves of both species. Low stomatal conductance and leaf water potential also occur in response to the dry season for both species, indicating that the forest species is also subjected to physiological consequences of the dry season, even though this species inhabits a moist environment, such as the riparian forest. We also demonstrate that wood anatomical features of these species support their performance in savanna and forest environments, respectively. While the forest species is more vulnerable to cavitation, which is probably related to its distribution in moist environments, the savanna species displays xylem safety to endure drought-prone habitats.

\section{Acknowledgements}

We acknowledge the Brazilian National Council for Scientific and Technological Development (CNPq) for a MSc scholarship granted to C.M.S. da Silva and for research productivity fellowships granted to G. Habermann, R. Harakava, R. V. Ribeiro and S. R. Machado. Authors acknowledge the Fundação de Amparo à Pesquisa do Estado de São Paulo (Proj. Fapesp Multiusuários, 2009/54208-6) and the CNPq (471452/2008-4 grant to GH) for financial support. We also thank Dr. 
Guilherme J. Zocolo for the assistance in measuring ABA and its metabolites at the Institute of Chemistry (Unesp, Araraquara, SP).

\section{References}

Arbellay, E., Fonti, P., Stoffel, M., 2012. Duration and extension of anatomical changes in wood structure after cambial injury. J. Exp. Bot. 63, 3271-3277.

Boursiac, Y., Léran, S., Corratgé-Faillie, C., Gojon, A., Krouk, G., Lacombe, B., 2013. ABA transport and transporters. Trends Plant Sci. 18, 325-333.

Brodribb, T.J., McAdam, S.A.M., 2011. Passive origins of stomatal control in vascular plants. Science 331, 582-585.

Bukatsch, F., 1972. Bemerkungen zur Doppelfärbung Astrablau-safranin. Mikrokosmos 61, 255.

Bustin, S.A., Benes, V., Garson, J.A., Hellemans, J., Huggett, J., Kubista, M., Mueller, R., Nolan, T., Pfaffl, M.W., Shipley, G.L., 2009. The MIQE guidelines: minimum information for publication of quantitative real-time PCR experiments. Clin. Chem. 55, 611-622.

Chaves, M.M., Pereira, J.S., Maroco, J., Rodrigues, M.L., Ricardo, C.P.P., Osório, M.L., Carvalho, I., Faria, T., Pinheiro, C., 2002. How plants cope with water stress in the field? Photosynthesis and growth. Ann. Bot. 89, 907-916.

Cutler, A.J., Krochko, J.E., 1999. Formation and breakdown of ABA. Trends Plant Sci. 4, 472-478.

Da Veiga, E.B., Habermann, G., 2013. Instantaneously measured traits may detect nonplastic ecophysiological performances in response to drought, explaining distributions of Styrax species in the Cerrado. Trees 27, 1737-1745.

Davies, W.J., Kudoyarova, G., Hartung, W., 2005. Long-distance ABA signaling and its relation to other signaling pathways in the detection of soil drying and the mediation of the plant's response to drought. J. Plant Growth Regul. 24, 285-295.

Ewers, F.W., Ewers, J.M., Jacobsen, A.L., López-Portillo, J., 2007. Vessel redundancy: modeling safety in numbers. Iawa J. 28, 373-388.

Feistler, A.M., Habermann, G., 2012. Assessing the role of vertical leaves within the photosynthetic function of Styrax camporum under drought conditions. Photosynthetica 50, 613-622.

Franco, A.C., Bustamante, M., Caldas, L.S., Goldstein, G., Meinzer, F.C., Kozovits, A.R., Rundel, P., Coradin, V.T.R., 2005. Leaf functional traits of Neotropical savanna trees in relation to seasonal water deficit. Trees 19, 326-335.

Franco, A.C., 1998. Seasonal patterns of gas exchange, water relations and growth of it Roupala montana: an evergreen savanna species. Plant Ecol. 136, 69-76.

Habermann, G., Bressan, A.C.G., 2011. Root, shoot and leaf traits of the congeneric Styrax species may explain their distribution patterns in the cerrado sensu lato areas in Brazil. Funct. Plant Biol. 38, 209-218.

Habermann, G., Ellsworth, P.F.V., Cazoto, J.L., Simão, E., Bieras, A.C., 2011. Comparative gas exchange performance during the wet season of three Brazilian Styrax species under habitat conditions of cerrado vegetation types differing in soil water availability and crown density. Flora-Morphology. Distrib. Funct. Ecol. Plants 206, 351-359.

Han, Y.-J., Cho, K.-C., Hwang, O.-J., Choi, Y.-S., Shin, A.-Y., Hwang, I., Kim, J.-I., 2012. Overexpression of an Arabidopsis $\beta$-glucosidase gene enhances drought resistance with dwarf phenotype in creeping bentgrass. Plant Cell Rep. 31, 1677-1686.

Hao, G.Y., Hoffmann, W.A., Scholz, F.G., Bucci, S.J., Meinzer, F.C., Franco, A.C., Cao, K.F., Goldstein, G., 2008. Stem and leaf hydraulics of congeneric tree species from adjacent tropical savanna and forest ecosystems. Oecologia 155, 405-415. http://dx. doi.org/10.1007/s00442-007-0918-5.

Heilmeier, H., Schulze, E.-D., Fan, J., Hartung, W., 2007. General relations of stomatal responses to xylem sap abscisic acid under stress in the rooting zone - a global perspective. Flora Morphol. Distrib. Funct. Ecol. Plants 202, 624-636.

Holbrook, N.M., Shashidhar, V.R., James, R.A., Munns, R., 2002. Stomatal control in tomato with ABA-deficient roots: response of grafted plants to soil drying. J. Exp. Bot. $53,1503-1514$

Hukin, D., Cochard, H., Dreyer, E., Le Thiec, D., Bogeat-Triboulot, M.-B., 2005. Cavitation vulnerability in roots and shoots: does Populus euphratica Oliv., a poplar from arid areas of Central Asia, differ from other poplar species? J. Exp. Bot. 56, 2003-2010.

Iuchi, S., Kobayashi, M., Taji, T., Naramoto, M., Seki, M., Kato, T., Tabata, S., Kakubari, Y., Yamaguchi-Shinozaki, K., Shinozaki, K., 2001. Regulation of drought tolerance by gene manipulation of 9-cis-epoxycarotenoid dioxygenase, a key enzyme in abscisic acid biosynthesis in Arabidopsis. Plant J. 27, 325-333.

Jasińska, A.K., Alber, M., Tullus, A., Rahi, M., Sellin, A., 2015. Impact of elevated atmospheric humidity on anatomical and hydraulic traits of xylem in hybrid aspen. Funct. Plant Biol. 42, 565-578,

Kissmann, C., Tozzi, H.H., Martins, S., Habermann, G., 2012. Germination performance of congeneric Styrax species from the Cerrado sensu lato areas and their distribution pattern in different physiognomies. Flora Morphol. Distrib. Funct. Ecol. Plants 207,
673-681.

Kissmann, C., da Veiga, E.B., Eichemberg, M.T., Habermann, G., 2014. Morphological effects of flooding on Styrax pohlii and the dynamics of physiological responses during flooding and post-flooding conditions. Aquat. Bot. 119, 7-14.

Kraus, J.E., Arduin, M., 1997. Manual básico de métodos em morfologia vegetal. Edur Rio de Janeiro.

López-Carbonell, M., Gabasa, M., Jáuregui, O., 2009. Enhanced determination of abscisic acid (ABA) and abscisic acid glucose ester (ABA-GE) in Cistus albidus plants by liquid chromatography-mass spectrometry in tandem mode. Plant Physiol. Biochem. 47, 256-261. http://dx.doi.org/10.1016/j.plaphy.2008.12.016.

Lee, K.H., Piao, H.L., Kim, H.-Y., Choi, S.M., Jiang, F., Hartung, W., Hwang, I., Kwak, J.M., Lee, I.-J., Hwang, I., 2006. Activation of glucosidase via stress-induced poly merization rapidly increases active pools of abscisic acid. Cell 126, 1109-1120.

Lewis, A.M., Boose, E.R., 1995. Estimating volume flow rates through xylem conduits. Am. J. Bot. 1112-1116.

Medrano, H., Escalona, J.M., Bota, J., Gulías, J., Flexas, J., 2002. Regulation of photosynthesis of C3 plants in response to progressive drought: stomatal conductance as a reference parameter. Ann. Bot. 89, 895-905.

Meinzer, F.C., 2003. Functional convergence in plant responses to the environment. Oecologia 134, 1-11.

Okamoto, M., Tanaka, Y., Abrams, S.R., Kamiya, Y., Seki, M., Nambara, E., 2009. High humidity induces abscisic acid 8'-hydroxylase in stomata and vasculature to regulate local and systemic abscisic acid responses in Arabidopsis. Plant Physiol. 149, 825-834.

Oliveira Filho, A.T., Ratter, J.A., 2002. Vegetation physiognomies and woody flora of the cerrado biome. In: Oliveira, P.S., Marquis, R.J. (Eds.), The Cerrados of Brazil Ecology and Natural History of a Neotropical Savanna. Columbia University Press, New York, NY, pp. 91-120.

Pinheiro, C., Chaves, M.M., 2011. Photosynthesis and drought: can we make metabolic connections from available data? J. Exp. Bot. 62, 869-882. http://dx.doi.org/10. 1093/jxb/erq340.

Prado, C.H.B. de A., Wenhui, Z., Cardoza Rojas, M.H., Souza, G.M., 2004. Seasonal leaf gas exchange and water potential in a woody cerrado species community. Brazilian J. Plant Physiol. 16, 7-16.

Sass, J.E., 1940. Elements of Botanical Microtechnique. Elem. Bot. Microtech.

Sauter, A., Davies, W.J., Hartung, W., 2001. The long-distance abscisic acid signal in the droughted plant: the fate of the hormone on its way from root to shoot. J. Exp. Bot. 52, 1991-1997.

Sauter, A., Dietz, K., Hartung, W., 2002. A possible stress physiological role of abscisic acid conjugates in root-to-shoot signalling. Plant. Cell Environ. 25, 223-228.

Silva, C.M., Habermann, G., Marchi, M.R.R., Zocolo, G.J., 2012. The role of matrix effects on the quantification of abscisic acid and its metabolites in the leaves of Bauhinia variegata L. using liquid chromatography combined with tandem mass spectrometry. Braz. J. Plant Physiol. 24, 223-232.

Tan, B.C., Joseph, L.M., Deng, W.T., Liu, L., Li, Q.B., Cline, K., McCarty, D.R., 2003. Molecular characterization of the Arabidopsis 9-cis epoxycarotenoid dioxygenase gene family. Plant J. 35, 44-56. http://dx.doi.org/10.1046/j.1365-313X.2003. 01786.x.

Thameur, A., Ferchichi, A., López-Carbonell, M., 2011. Quantification of free and conjugated abscisic acid in five genotypes of barley (Hordeum vulgare L.) under water stress conditions. South Afr. J. Bot. 77, 222-228.

Thompson, A.J., Thorne, E.T., Burbidge, A., Jackson, A.C., Sharp, R.E., Taylor, I.B., 2004. Complementation of notabilis, an abscisic acid-deficient mutant of tomato: importance of sequence context and utility of partial complementation. Plant. Cell Environ. 27, 459-471.

Thompson, A.J., Mulholland, B.J., Jackson, A.C., McKee, J.M.T., Hilton, H., Symonds, R.C., Sonneveld, T., Burbidge, A., Stevenson, P., Taylor, I.B., 2007. Regulation and manipulation of ABA biosynthesis in roots. Plant. Cell Environ. 30, 67-78.

Turner, N.C., 1981. Techniques and experimental approaches for the measurement of plant water status. Plant Soil 58, 339-366.

Tyree, M.T., Ewers, F.W., 1991. The hydraulic architecture of trees and other woody plants. New Phytol. 119, 345-360.

Umezawa, T., Okamoto, M., Kushiro, T., Nambara, E., Oono, Y., Seki, M., Kobayashi, M., Koshiba, T., Kamiya, Y., Shinozaki, K., 2006. CYP707A3, a major ABA 8'-hydroxylase involved in dehydration and rehydration response in Arabidopsis thaliana. Plant J. 46, 171-182.

Xiong, L., Zhu, J.-K., 2003. Regulation of abscisic acid biosynthesis. Plant Physiol. 133, 29-36.

Yang, J., Guo, Z., 2007. Cloning of a 9-cis-epoxycarotenoid dioxygenase gene (SgNCED1) from Stylosanthes guianensis and its expression in response to abiotic stresses. Plant Cell Rep. 26, 1383-1390.

Zaharia, L.I., Walker-Simmon, M.K., Rodríguez, C.N., Abrams, S.R., 2005. Chemistry of abscisic acid, abscisic acid catabolites and analogs. J. Plant Growth Regul. 24, 274-284. 